\title{
ACTIVE CLASSROOMS ENABLING REGIONAL, NATIONAL AND GLOBAL COLLABORATION
}

\author{
P. Holland ${ }^{1}$, P. Davies ${ }^{1}$, C. Arnold 1 , J. Leon ${ }^{2}$, N. Hilaireau', M. Alves ${ }^{2}$, K. Ennser ${ }^{1}$, \\ S. Cahill ${ }^{1}$, M. Hainke ${ }^{1}$ \\ ${ }^{1}$ Swansea University (UNITED KINGDOM) \\ ${ }^{2}$ Texas A\&M University (UNITED STATES)
}

\begin{abstract}
Many higher education institutions are considering the transition to active learning approaches. Traditional lecture theatre settings are used, but some of the most effective techniques such as design-based learning are easiest to apply in collaborative group spaces. However, the costs of building new learning spaces can be prohibitive while convincing busy staff to re-think their teaching approach an unenviable task. In this work, the journey to Swansea University's first reconfigurable computer lab and active learning studio is explored as an approach to solving both these issues and opening doors to innovation and new programmes. Feedback is presented from both staff and students to show the impact on student learning and the adoption of new pedagogies.

The introduction of the active learning studio has led to new initiatives, including funding to link a Swansea University collaborative space with further education colleges in the region. It has also led to the College of Engineering at Swansea being invited to join a globally delivered group design module with partners in the US, Brazil and France. This collaborative approach paves the way for consideration of new funding and educational models where students can study elective modules outside their home institutions while retaining the benefits of active methods.
\end{abstract}

Keywords: Active Classrooms, collaboration, collaborative learning.

\section{INTRODUCTION}

A change in pedagogical approach is being explored at many United Kingdom Higher Education Institutes (HEIs). The traditional primary teaching delivery mode of lectures is increasingly being challenged as academic staff adopt new pedagogies. There are many drivers for this change in teaching practices, including the motivations of teachers to enable deeper learning and develop key skills in their students. While changes in teaching practices often occur organically and incrementally over relatively long periods, the pace of change to active learning approaches and the resulting impact on learning spaces is being accelerated by external stimuli in the UK and other countries. Increased competition between HEls due to marketisation are driving initiatives to increase teaching quality, improve the student experience and meet the challenges associated with rapid advances in digital technologies [1-4]. With this fast-moving background, academic teaching staff may be asked to use different types of learning spaces requiring different delivery approaches and before they have encountered other academic staff using active learning approaches. Providing the evidence underpinning active learning approaches, the need for development of new types of learning spaces, training in how they may be used for both staff and students, and case studies of different use cases are essential considerations for HEls encouraging this change.

The movement to create active learning studios (ALSs) is not new but has developed over the last few decades. Pedagogical research in the United States in the 1970s and 1980s explored the benefits of constructive activity in small collaborative groups. Researchers observed the positive effects when students help each other learn. Students can construct new knowledge and internalise problemsolving methods to correct misconceptions by sharing approaches jointly with others [5]. As this small group pedagogical research developed and provided data-driven evidence of differences in conceptual understanding between delivery modes; pioneers of active learning approaches began to experiment with new digitally enabled learning spaces. The first ALSs, where small groups of students are seated on collaborative tables in digitally enhanced rooms began to appear in the 1990s with examples at Rensselaer Polytechnic Institute, the SCALE-UP project at North Carolina State University with wider adoption from 2003 after the Technology-Enhanced Active Learning project at the Massachusetts Institute of Technology (MIT) [6]. 
In parallel with the introduction of active learning studios in the 90 s, social constructivism theory underpinning small group collaborative and active learning approaches began to gain further traction with other researchers creating momentum and movement away from teacher-directed activities in lecture format to a more student-centred approach as described in the 'Sage on the Stage to Guide on the Side' paper from King in 1993 [7]. While social constructivism theory typified in many active learning approaches such as team-based and design-based learning can be used in any environment including lecture theatres, further developments led to the belief that studio designs facilitating small group work at tables were the best way to deliver it. With the advent of widespread adoption of Learning Management Systems (LMS) in HEls worldwide, the concept of the flipped classroom became increasingly used where primary knowledge transfer through pre-reading materials, $[8,9]$ and later through streamed videos [10], occurs online enabling subsequent face-to-face teaching to use small group active learning approaches to construct deeper understanding and embed knowledge. While the effectiveness of active learning approaches has been proven in studies of STEM subjects [11], the flipped classroom method of delivering it while widely adopted is questioned for its effectiveness [12]. Students can lose the skills of the lecturer in providing scaffolding to help students understand threshold concepts vital to subject mastery unless additional sense-making activities are introduced in the learning design [13]. Similarly, other researchers argue that lower-tech studios using analogue tools such as whiteboards and pen/paper are as effective as digital rooms and active learning in lectures may be a more cost-effective approach [14].

In this paper, we describe the journey to the instalment of new ALSs in the College of Engineering (CoE) at Swansea University (SU). Staff and student feedback on the decision to invest and the use of the spaces are explored. We show how the extra functionality available in an ALS may be used for new approaches to active distance learning and conclude with a reasoned argument that the decision to invest in new learning spaces is complex and consideration goes beyond comparisons of efficacy of delivery modes as often seen in the literature.

\section{INFLUENCES AND ESTABLISHMENT OF FLEXIBLE ACTIVE SPACES}

Swansea University staff from across the institution worked together in 2018 to install a new ALS. While the exact motivations may have differed by department and job function, the common goal of improving student learning and experience was the same. For example, the estates department were driven by timetabling requirements to create an additional computer laboratory suitable for all stakeholders; student experience staff wanted to respond to student feedback for more group workspaces available in the daytime and evenings; while academic and professional services staff wanted to evaluate and introduce more active learning approaches into degree programmes to improve the engagement and deep learning of students.

\subsection{Sector Influences and Internal Developments}

The knowledge that it may be possible to meet the collective aspirations of all stakeholders for multipurposed teaching spaces was acquired from external influences. Academic staff in the College of Engineering (CoE) who form part of the Learning and Teaching Enhancement Centre (LTEC) and a senior professional services staff member of the Swansea Academy of Learning and Teaching (SALT) travelled together to an event in July 2016. Hosted by the University the Southampton, the event was titled 'STEM pedagogies: Best practice considerations' and talks included the flipped classroom and use of social media to increase student engagement and led to staff trialling new pedagogies at SU $[15,16]$. Another insightful event attended by LTEC staff included the 'New Approaches to Engineering Higher Education' conference hosted by the Engineering Professors Council (EPC) and The Institute of Engineering and Technology (IET) [17]. The conference described a global sea change in thinking about higher education with a focus on bringing more active learning to engineering courses. Many of the talks focused on how some HEls were investing in ALSs at various scales to enhance student learning and develop the key skills required for successful careers in the digital age.

In February 2018 the Pro-Vice Chancellor for Learning and Teaching, the Dean of Educational Technology, the President of the student union and a member of the IT department from SU visited Texas A\&M University to understand the rationale for the significant investment in a new learning and teaching initiative. The Zachry Engineering Education Complex (ZEEC) building is a $\$ 228 \mathrm{M}$ investment to bring active learning approaches to the engineering undergraduate students with a student-centred design and modern learning techniques and technology [18]. The learning spaces include 18x96 seater, and 14x48 seater ALSs and are available to all faculty, who can access training 
courses on active learning. Feedback from faculty post-training was positive with many adopting active learning approaches. Heavily influenced by the vision for the ZEEC building, LTEC and SALT staff with senior management sponsorship were able to arrange for a pop-up ALS called the 'Sticky Campus Roadshow' to visit SU to help show that other alternatives to learning space design and pedagogical approach were possible and being used effectively elsewhere [19]. The pop-up studio was used for a wide variety of activities including open student study sessions; bespoke training courses on active learning; college learning and teaching meetings delivered using design thinking workshops; digital strategy meetings; estates meetings and student classroom sessions for live modules. After the visit of the roadshow there was enough interest, knowledge generated and positive feedback from academic staff, students and professional services staff to look for opportunities to establish permanent ALSs.

\subsection{Establishment of Reconfigurable Computer Lab to Active Learning Space}

An opportunity to establish an ALS at SU arrived during the summer of 2018 when a new computer laboratory was required to meet timetabling demands at the Bay Campus and former office space, A019, was chosen to be refitted. The learning spaces group designed two layouts for the space. The first was a traditional design with pcs seated on rows of individual desks and repeater screens at the end of each row, so each student could directly view the content being presented on a projector. The other design was reconfigurable with pcs located on synergy tables that seat six people with a collaborative screen at the end of each table. However, the computers can also fold down inside the specialised tables, and the room becomes an ALS where students can work in teams allowing the use of active learning approaches. The reconfigurable version was also specified to use an application enabling students to use their own devices to control the collaborative screens and the lecturer to share any collaborative screen content to all the others, and projector screens. An academic staff survey was used to decide which design to use, and the result was overwhelmingly in favour of the reconfigurable layout, where $90 \%$ of colleagues thought it more flexible for teaching and beneficial to the student experience. By taking a blended team approach the estates' staff also understood that academics appreciate high-quality learning environments and that pressure to maximise the number of seats must be balanced with staff and student feedback. Additionally, feedback from the staff also showed how vital exposure to the Sticky Campus Roadshow had been in giving them an understanding of the purpose of the ALS so that they made an informed decision. The design of A019 is inventive as it allows lecturers to teach traditionally when the pcs are raised or using active learning approaches when they are folded away, giving options for gradual experimentation and change in delivery as shown in Fig 1.

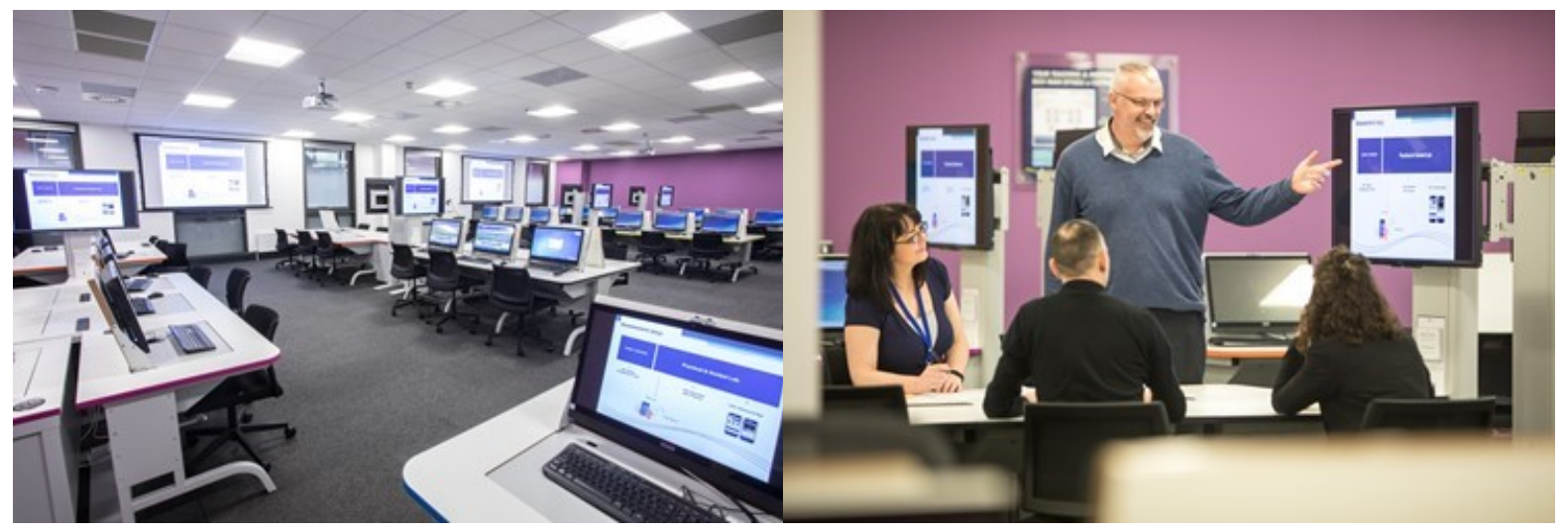

(a)

(b)

Figure 1. A019 (a) Reconfigurable Computer Lab to (b) Active Learning Studio

\subsection{The Growing Comms Project and Linked Spaces}

An opportunity to combine the knowledge gained in establishing the first CoE ALS with staff confidence and know-how generated in participation in 'Invent for the Planet' (section 3.4) came when the Higher Education Funding Council for Wales (HEFCW) announced a funding call titled 'Enhancing HE-FE Collaboration in Innovation \& Engagement Activity' in 2018. Further Education (FE) partner institutions Gower College Swansea, NPTC Group of Colleges and Pembrokeshire College joined with SU to submit the Growing Regional Outputs With Innovative Next Generation Communications 
(Growing Comms) grant application. Growing Comms was successful and funded in August 2018 and is designed to stimulate regional growth through two workstreams. It will increase engagement, innovation and technology transfer between industry and education institutes while creating more opportunities for enhanced training, skills and education. The funds from the grant have been used to create ALSs at each institution that are linked using modern virtual collaborative platforms. The linked rooms across the region will act as innovation hubs and learning spaces where face-to-face activities can be merged with online collaboration. The new ALS in the CoE at SU used the staff and student feedback from A019 and has both digital and analogue educational technologies to enable best practices in multi-modal delivery. Emerging case studies from the Growing Comms project are described in sub-sections 3.2 and 3.3.

\section{LEARNING FROM INTERNAL USE AND COLLABORATION CASE STUDIES}

Well-designed active classrooms enable high-quality learning activities and deeper learning [11]. Introducing digital technologies into these spaces can expand the usefulness of the rooms beyond what is possible in only analogue spaces. Therefore, when designing new learning spaces, careful consideration should be given to what activities are required and the functionality of the technology to achieve them. The costs of installing digital technologies may be expensive, and the experience at Swansea University shows that investment should be justifiable to all stakeholders to achieve consensus. The key points learned from the first active studio installation to achieve a successful outcome include making time for leadership of the initiative; creating a collective vision for all stakeholders through presentations and question and answer sessions to justify time and expenses to do things differently; and, supporting all colleagues internally so that all aspects surrounding the installation of ALSs such as training on the technology and pedagogical approach all interleave seamlessly. In the following case studies, examples are given to show the extra value of the digitally enabled ALS and how collaborative screens; personal computers (PCs); Wi-Fi enabled connectivity between all devices; and linked spaces using cloud-based virtual collaborative platforms enable increased opportunities for collaboration and innovation.

\subsection{Enhanced Internal Module Delivery}

It is best practice to evaluate the successes of previous learning space designs and consider opportunities to improve them to achieve outstanding teaching facilities [20]. One of the modules taught in the reconfigurable computer laboratory to active learning space, A019, in semester 1, 2018 was a final year undergraduate management module titled 'Application Development'. This module was assessed by coursework with linked written authentic assignments and the production of a fully featured and deployable smartphone application. The learning activities were well aligned with the learning outcomes and assessments. Students used the active set-up in the studio to problem solve or design together in groups using the plectrum tables and collaborative screens and benefited from peer learning and constant feedback through interaction with other students and the lecturer. When a student was required to produce coding for the final application assessment, they were able to work individually by raising the PC normally located inside the desk. The lecturer was able to digitally transmit the screen of each table to all the other tables, allowing each group to share their ideas with all the other students developing communication and other key skills. For this module, the learning space mimics how digital teams might work in industry, that is by understanding macro-problems together before splitting them into micro-elements which they can work on individually and then reassemble. For this type of management module and many others in computer science and engineering disciplines, an ALS offers additional advantages when the learning outcomes include the use or mastery of software or coding. However, interestingly the lecturer delivering the module also used paper, pens, posters and re-arrangement of seating to allow huddle groups and presentations showing that more traditional learning technologies are still required.

Student feedback for this module was positive and the lecturer nominated for teaching awards at SU. Student comments that were typical of the whole cohort include: -

"All of the lab sessions were extremely engaging and informative. Having an environment where even the more shy individuals feel comfortable speaking up made such a huge difference in being able to learn the material."

Other comments reinforced this positive feedback about the benefits of peer instruction but specifically referred to the design of the teaching space: - 
"This new lab promotes enhanced pedagogy and equips us with all the possible tools required for this module to interact, engage, learn and work."

While other student feedback comments focused on the relaxed and authentic learning environment that is often a benefit of facilitated active sessions: -

"The hands-on learning, and doing coursework that gives us experience of what we will do when we graduate", "The teaching labs created a great atmosphere to learn".

In addition to the student feedback, it was very valuable for multi-disciplinary learning spaces team to take staff feedback and for this module the lecturer gave direct feedback: -

"I wanted to express my thanks for making A019 in Engineering happen. My $3^{\text {rd }}$ years and I used this new space in multiple ways this week and it's a really supportive (and cool) learning environment. They did formative peer presentations to each other and then we folded the pc's down allowing real social \& peer learning / communication between students on the tables. I can't tell you how much this helps promote learning (compared to standard PC lab layout) and the students appreciate it too. Couple of pics attached to show you what I mean, it's worth expressing our gratitude, and really thank you all."

The lecturer also fed back verbally that it would be useful to have some whiteboards fitted in the room to enable more traditional learning activities when appropriate. This feedback was highly informative for the learning spaces group and used in designing the new active learning space for the Growing Comms project which has a mix of digital and analogue features, meeting the current and future needs of the academic staff.

\subsection{Regional Collaboration with Further Education Institutions}

The Growing Comms project was designed to use digitally enhanced learning spaces and modern software-based communication platforms to grow regional development by improved collaborative working. At the regional level in Wales, travel time is still relatively short, thus allowing models of collaboration to include local travel. The following case studies show examples of how a combination of group or individual activities synchronously online, asynchronously online and physically face-toface can enhance collaboration and add value.

\subsubsection{Enhanced Student Visits}

Part of the outputs for the Growing Comms project are to ensure that FE students gain understanding about the relationship between HE and future employment [21]. The FE partners in this project were funded to bring their students to visit SU or other HEls. For example, to maximise the value and impact of a visit by 60 engineering students in December 2019, additional learning activities are being designed for delivery between the linked active classrooms before the visit. The FE students will be asked to watch a presentation online about a topical subject, in this case, how to align sustainable energy generation with consumption patterns to reduce carbon emissions from fossil fuels. The students will have an opportunity to discuss the problem with their fellow students at their local ALS and with other FE/HE students and staff using the linked classroom features. Arriving at SU the students will experience a master lecture on the issue followed by a tour of research facilities, working collaboratively to find solutions. They will participate in a design thinking workshop in the active classroom, brainstorming solutions and talking to industry partners who will help facilitate the session. While some of these types of activities happen in current visits, the application of synchronous and asynchronous online learning and active spaces is being trialled to evaluate if they add increased value through alignment and enable a deep experiential learning experience [22].

\subsubsection{Distributed Learning Courses for FE/HE Staff}

Another example of this collaborative approach of combining online learning with face-to-face activities at the regional level is the current planning to use the linked spaces in the Growing Comms project to offer a distributed learning course on virtual reality application development software for staff at our FE partners. With VR technology a key tool for future industry needs, this course provides an opportunity to enhance future skills and create a more work-ready workforce. Teaching a course using asynchronous online materials and synchronously in a linked active classroom to all partners using a webinar software solution enables courses to be run in the evenings without travel to one site. Trainees can learn in teams at their local site, including staff present in the room at SU with all benefitting from collaborative peer learning and saving time and travel costs. Communication at table 
level between sites allows for enhanced team building and an improved learning community. At the regional level it is also possible for the trainer to travel to different sites in rotation to establish or take advantage of building relationships through face-to-face activities [23, 24].

\subsection{National Collaboration with Further Education \& Industry}

At the national level, there are opportunities to reinforce collaboration models with virtual mobility. The Growing Comms project is focusing on enhanced synchronous online activities, such as enabling active learning pedagogies at distance and the use of the active learning spaces for innovation and collaboration with industry. Creation of such models will offer flexibility for training needs in industry with minimal disruption to the daily business need.

\subsubsection{Delivery on Industry-based schemes}

In Wales, synchronous delivery of teaching over distance has predominantly relied on the use of more traditional lecturing approaches using videoconferencing services provided by the Welsh Video Network (WVN) [25]. In this approach videoconference rooms are linked by video and audio, and the lecturer teaches via a camera, with the students looking at a monitor at the other end. An excellent example of this type of activity is the ground-breaking BEng in Aeronautical and Manufacturing Engineering apprenticeship degree that is a collaboration between Coleg Cambria and Airbus, both located in North Wales and Swansea University in South Wales [26]. For the final two years of this four-year programme Swansea University staff teach some of the modules with a combination of faceto-face teaching at both the Coleg Cambria campus and to the students on the programme who travel to SU. Some synchronous online teaching is also used for example classes and delivered through the WVN videoconference rooms at each campus. Through the Growing Comms project, the partners are trialling new collaboration software enabling more interaction in example classes between the students and staff enabled via electronic whiteboards and multiple devices. This approach facilitates the use of new pedagogies such as design-based learning approaches so that students benefit from a broader range of learning activities where that would only usually be possible if the instructor was present faceto-face. For example, the SU instructor has added presentations from students on mini-research reviews; online review of design outlines with students sharing content through their own devices and more student participation in discourse through open question and answer sessions.

\subsubsection{Multiple site delivery for Further Education Courses}

One of the FE partners on the Growing Comms project, NPTC Group of Colleges has multiple campuses in Mid and South Wales and are installing two linked spaces at the Neath campus and Newtown campus that are over $145 \mathrm{~km}$ apart and over two hours travel time by car. By digitally linking the ALSs, NPTC will trial the delivery of existing courses to two sites. Students who value the support and peer learning in a face-to-face environment will be able to access educational programmes that would otherwise not have enough students to be financially viable. The project is creating opportunities for virtual mobility outside of only online courses and helping to create learning communities that can benefit from meeting physically and use active learning approaches at multiple sites.

\subsection{Global Collaboration with Higher Education Institutes}

The COE at SU is participating in two initiatives established by one of their largest strategic $\mathrm{HE}$ partners, Texas A\&M University. Both initiatives may be described as examples of globally networked learning courses although they differ in purpose and educational design [27].

\subsubsection{Invent for the Planet}

Invent for the Planet is a 48-hour intensive global design learning experience hosted by the Texas A\&M College of Engineering that focuses on solving shared global challenges. HEls and industrial partners produce 'need statements' that are distributed to over 24 partner universities across the world in advance of the weekend event. Each university partner advertises the opportunity and student volunteers are formed into teams based on their choice of which need statement most interests them. Over the weekend of the competition they follow design thinking processes and work with academic facilitators both at their home institution or to international expert volunteers using virtual collaboration tools. By the end of the weekend, teams produce design concepts, prototypes and elevator pitches which are judged by a panel of experts at their home university. The winners then video their pitch which is judged by experts at Texas A\&M, and five teams are selected to travel to Texas for a grand 
final. Swansea University CoE used its first in the 2019 event, and both staff and students commented on how much the ALS enhanced the learning experience and team performance, undoubtedly a factor in a Swansea team placing third in the overall competition [28]. Running events like Invent for the Planet demonstrate how well-designed physical and digital spaces improve GNL learning environments.

\subsubsection{ENGR410 Global Engineering Design}

Engineering graduates often work for multinationals or work for companies that deliver projects for international partners, so they must have global mindsets and the design skills to work across countries and cultures successfully. The ENGR410 Global Design Engineering module is delivered internationally to students from Texas A\&M, Federal University of Rio de Janeiro, Arts et Métier (ENSAM) France and Swansea CoE. Students learn about; intercultural models and their application to engineering design in diverse, multinational and multidisciplinary settings; modern design thinking approaches and use of virtual collaboration tools. Delivery of the course content is a combination of synchronous and asynchronous delivery approaches, blending traditional face-to-face delivery for home students, with web-based lectures and content to international partner HEls. The students form international and multi-disciplinary teams to work on challenging industrial design projects using appropriate virtual platforms, embedding the collaborative practices they have learnt in lectures. This course enables a deep experiential learning experience that helps differentiate students when finding graduate positions. The CoE at SU has been able to join this module for the first time this year through developing staff confidence in and knowledge of virtual collaboration tools and skills in using active pedagogies [29]. Opportunities to grow the student numbers or develop larger co-delivered modules in the new active learning studios are being pursued demonstrating how the capabilities of ALSs enable innovation and new models for international HE collaboration.

\section{CONCLUSIONS}

In this work, the journey to the first ALSs in the CoE at SU is documented. Reflection on the approach to creating stakeholder momentum towards installing new spaces shows that it is vital to provide leadership through a vision of what is possible with active learning, how to achieve it, and present information on what is happening at other HEls.

There is an academic debate about the need for technology in active classrooms and the efficacy of the flipped classroom pedagogical approach. However, in this work we take a more pragmatic view of the reasons for investment in a small number of ALSs and leave the broader discussions on pedagogical drivers for them for later after more staff and student use.

We take a case study approach to demonstrate that ALSs are well-received learning environments for 'internal' modules, especially those where the learning outcomes include the mastery of software and key skills such as teamwork. With careful design the spaces may be used flexibly for traditional teaching or active learning approaches. However, importantly we show how digital technologies in studios add extra value when used for collaboration outside the HEI for distributed learning at regional or national level and for globally networked learning courses with international $\mathrm{HEI}$ and industry partners.

Active classrooms can enable a whole lot more than active learning. They can fill a new gap as virtual mobility drivers, including democratisation of $\mathrm{HE}$ and climate change crisis increasingly demand change in educational and funding models. We conclude that justification for investment in ALSs is not limited to learning gain and student experience but is more complex and HEls must consider a wider range of factors in their decision making and governance procedures.

\section{ACKNOWLEDGEMENTS}

The authors would like to thank all the students, professional services and academic staff at our partner institutions including Coleg Cambria, Gower College Swansea, NPTC Group of Colleges, Pembrokeshire College, Texas A\&M University and at Swansea University for their help in making the introduction of active learning studios a success. We would also like to thank HEFCW for funding the Growing Comms project. 


\section{REFERENCES}

[1] R. Sullivan-Jones, "How the UK HE sector functions as a market, and why it warrants analysis," Times Higher Education, Times Higher Education, 2017.

[2] Jisc, Mobile Learning, United Kingdom, 12 November 2015.

[3] T. B. Newman, Helen, and S. Knight, "Digital experience insights survey 2018: findings from students in UK further and higher education," Jisc, 2018.

[4] O. f. Students. "Teaching Excellence and Student Outcomes Framework," 23 September 2019, 2019; https://www.officeforstudents.org.uk/for-students/the-tef/.

[5] N. M. Webb, J. D. Troper, and R. Fall, "Constructive activity and learning in collaborative small groups," Journal of Educational Psychology, vol. 87, pp. 406-423, 1995.

[6] R. J. Beichner, "History and Evolution of Active Learning Spaces," New Directions for Teaching and Learning, vol. 2014, no. 137, pp. 9-16, 2014.

[7] A. King, "From Sage on the Stage to Guide on the Side," College Teaching, vol. 41, no. 1, pp. 3035, 1993.

[8] C. H. Crouch, and E. Mazur, "Peer Instruction: Ten years of experience and results," American Journal of Physics, vol. 69, no. 9, pp. 970-977, 2001.

[9] W. J. Baker, ""The "Classroom Flip": Using Web Course Management Tools to Become the Guide by the Side"," in International Conference on College Teaching and Learning, 2000.

[10] J. Bergmann, and A. Sams, Flip your classroom: reach every student in every class every day, Alexandria, Va: International Society for Technology in Education, 2012.

[11] S. Freeman, S. L. Eddy, M. McDonough et al., "Active learning increases student performance in science, engineering, and mathematics," Proceedings of the National Academy of Sciences, vol. 111, no. 23, pp. 8410-8415, 2014.

[12] E. Setren, K. Greenberg, O. Moore et al. "Effects of the Flipped Classroom: Evidence from a Randomized Trial," 10/09/2019, 2019; http://seii.mit.edu/wp-content/uploads/2019/08/SEIIDiscussion-Paper-2019.07-Setren.pdf.

[13] A. Armellini. "Active blended learning at Northampton, an update from the new campus," 10/10/2019, 2019; https://www.slideshare.net/JISC/opening-session-active-blended-learning-atnorthampton-an-update-from-the-new-campus.

[14] P. M. Baeplar, J. D. Walker, D. Brooks et al., A guide to teaching in active learning classrooms: History, research, and practice: Stylus Publishing, 2016.

[15] P. Holland, and R. Kerton, "Flipped, Authentic and Problem-Based Labs," in Active Learning Conference 2017, Anglia Ruskin University, 2017.

[16] P. M. Holland. "Championing Active Learning Approaches: A Vehicle for Institutional Change," 10/10/2019, 2019; https://www.heacademy.ac.uk/system/files/downloads/3.3b\%20-\%20 Holland.pdf.

[17] T. IET, "New Approaches to Engineering Higher Education."

[18] "Zachry Engineering Education Complex," 12th November 2018, 2018; https://zachry.tamu.edu/.

[19] Jisc. "Sticky campus roadshow," 26th September 2019, 2019; https://www.jisc.ac.uk/ rd/projects/ sticky-campus-roadshow.

[20] G. e. a. Ferrell, "The UK Higher Education Learning Space Toolkit," UCISA, 2016.

[21] "Graduates more likely to be in employment and earn more than non-graduates - new statistics," 10/10/18, 2018; https://www.universitiesuk.ac.uk/news/Pages/Graduates-more-likely-to-be-inemployment-and-earn-more-than-non-graduates-new-statistics.aspx.

[22] B. C. Czerkawski, "Designing Deeper Learning Experiences for Online Instruction," Journal of Interactive Online Learning, vol. 13, no. 2, pp. 29-40, 2014.

[23] M. Zelihic, "Relationship building in the online classroom," Developments in Business Simulation and Experiential Learning, vol. 42, 2015. 
[24] E. Stacey, and P. Gerbic, "Success factors for blended learning," in Ascilite 2008, Melbourne, 2008.

[25] WVN. "Welcome to the Welsh Video Network, home of public sector videoconferencing in Wales," 10/10/2019, 2019; http://www.wvn.ac.uk/en/.

[26] Cambria. "An engineering degree has taken off thanks to a college partnership with a worldleading plane maker," 10/10/2019, 2019; https://www.cambria.ac.uk/an-engineering-degree-hastaken-off-thanks-to-a-college-partnership-with-a-world-leading-plane-maker/.

[27] D. Starke-Meyerring, M. Wilson, R. D. Crabtree et al., Designing Globally Networked Learning Environments: Visionary Partnerships, Policies, and Pedagogies: DigitalCommons@Fairfield, 2008.

[28] Engineering. "Invent for the Planet," 10/10/2019, 2019; https://www.swansea.ac.uk/ texas/ teaching/iftp/.

[29] Various. "Open Virtual Mobility," 10/10/2019, 2019; https://www.openvirtualmobility.eu/. 